\title{
VERZEICHNIS DER ZAHLENTAFELN
}

Glühlicht-Beleuchtung. Seite

Leuchtdichte einiger Lichtquellen $\ldots \ldots \ldots \ldots \ldots \ldots \ldots \ldots, 2$

Durchlassung und Rückstrahlung verschiedener Glasarten . 3

Wahl der angenäherten Lampengröße.............. 5

Beleuchtungsstärke......................... 6 und 7

Einfluß von Spannungsabweichungen auf Glühlampen .... 11

Gebräuchlichste Glühlampentypen ................ 12

Rückstrahlung von emaillierten Blechen und Metallfolien .. 14

Elektromotoren.

Vergleich der Leistungen von Motoren, Menschen und Tieren 34

$\mathrm{kW}$ umgerechnet in PS....................... 34

Drehmomente von Motoren bei bestimmten Leistungen und

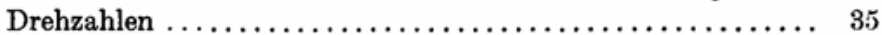

Verhältnis des Anlaufstromes zum Normalstrom......... 35

Ungefähre Normalstromstärke, Kupferquerschnitt und Sicherung in der Zuleitung von Gleichstrommotoren......... 37

Ungefähre Normalstromstärke, Kupferquerschnitt und Sicherung in der Zuleitung von Drehstrommotoren .......... 38

Wahl der Ausschalter bei kleinen Motoren ............. 39

Belastung von Straßenbrücken, Zwischendecken und Treppen bei Aufstellung von Motoren .................... 47

Tragfähigkeit von Osen und von S-Haken ............ 50

Zulässige Belastung von Hanfseilen, Drahtseilen und Ketten

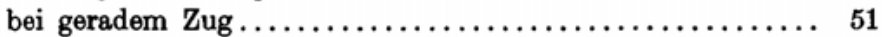

Zulässige Stützbelastung (Knickbelastung) von Holzbalken . 51

Zulässige Biegungsbelastung von Holzbalken und Eisenträgern 52

Durchmesser von Transmissionswellen in $\mathrm{mm}$ bei angegebener Drehzahl und Leistung $\ldots \ldots \ldots \ldots \ldots \ldots \ldots \ldots \ldots \ldots, 52$

Riemengeschwindigkeit aus Scheibendm. und Drehzahl.... 53

Anzahl der von je $1 \mathrm{~cm}$ Riemenbreite zu übertragenden PS 53

\section{Leitungen und thre Verlegung.}

Mindestquerschnitte der Leitungen.................. 56

Bemessung des Querschnitts isolierter Leitungen mit Rücksicht auf Erwärmung $\ldots \ldots \ldots \ldots \ldots \ldots \ldots \ldots \ldots \ldots, \quad 57$

\section{IX}


Berechnung des Leitungsquerschnittes aus der Leistung oder Stromstärke nach dem Spannungsabfall............. 58

Durchhang des Drahtmaterials bei kurzen Freileitungsstrecken 60 Mindestabstände von Leitungen ................. 62 Metallwandstärken von Peschelrohren, Isolierrohren und Stahlpanzerrohren .............................. 65

Lichte Weite von Peschelrohren, Isolierrohren, Gasrohren für eine oder mehrere isolierte Leitungen auf und in der Wand Leitungswiderstände und zulässige Strombelastungen für Peschelrohre ............................. 79 Leitungswiderstand des Kupferleiters und des Blechmantels bei Rohrdrähten............................ 84

\section{Installation von Wohnhäusern.}

Querschnitt der Steigeleitung $\ldots \ldots \ldots \ldots \ldots \ldots \ldots \ldots \ldots, 94$

Querschnitt der Verteilungsstromkreise ............. 105

Belastungstafel für Drehschalter ................. 107

\section{Installationen in Geschäftshäusern und dergl.}

Mittlere Kopierzeit zur Herstellung von Lichtpausen....... 134 Scheinwerferbeleuchtung für photogr. Reproduktion ....... 136 Arbeitsmaschinen in Geșchäftshäusern und Gasthöfen..... 142

\section{Elektrische Motoren und Heizapparate in gewerblichen Betrieben.}

Jährliche Benutzungsdauer der Motoren in kleingewerblichen Betrieben ............................... 157 Leistungsbedarf von Bäckerei- und Fleischerei-Maschinen ... 158 Leistungsbedarf von Metallbearbeitungsmaschinen ........ 162 Arbeitsergebnisse mit $1 \mathrm{kWh}$ bei elektromotorischem Antrieb von Werkzeugmaschinen $\ldots \ldots \ldots \ldots \ldots \ldots \ldots \ldots \ldots \ldots \ldots . \ldots \ldots$ Elmo-Tischbohrmaschinen zum Bohren in Metall......... 163 Elmo-Handbohrmaschinen zum Bohren in Metall ......... 164

Schmiedefeuergebläse $\ldots \ldots \ldots \ldots \ldots \ldots \ldots \ldots \ldots \ldots \ldots \ldots \ldots .165$

Schweißmaschinen ............................. 166

Elmo-Handbohrmaschinen zum Bohren in Holz.......... 169

Tragbare Holzbearbeitungsmaschinen............... 170

Ortsfeste Holzbearbeitungsmaschinen .............. 176

\section{Unfall- und Feuersicherheit.}

Elektrische Unfälle in den Jahren 1897, 1907, $1917 \ldots \ldots \ldots \ldots 207$

Entstehungsursachen der Brände 1914-1918 .......... 209 